\title{
Experimental study of the performances of commercial surfactants in reducing interfacial tension and wettability alteration in the process of chemical water injection into carbonate reservoirs
}

\author{
Siamak Najimi ${ }^{1} \cdot$ Iman Nowrouzi ${ }^{2}$. Abbas Khaksar Manshad ${ }^{3} \cdot$ Amir H. Mohammadi $^{2}$
}

Received: 18 July 2019 / Accepted: 30 September 2019 / Published online: 26 October 2019

(C) The Author(s) 2019

\begin{abstract}
Surfactants are used in the process of chemical water injection to reduce interfacial tension of water and oil and consequently decrease the capillary pressure in the reservoir. However, other mechanisms such as altering the wettability of the reservoir rock, creating foam and forming a stable emulsion are also other mechanisms of the surfactants flooding. In this study, the effects of three commercially available surfactants, namely AN-120, NX-1510 and TR-880, in different concentrations on interfacial tension of water and oil, the wettability of the reservoir rock and, ultimately, the increase in oil recovery based on pendant drop experiments, contact angle and carbonate core flooding have been investigated. The effects of concentration, temperature, pressure and salinity on the performances of these surfactants have also been shown. The results, in addition to confirming the capability of the surfactants to reduce interfacial tension and altering the wettability to hydrophilicity, show that the TR-880 has the better ability to reduce interfacial tension than AN-120 and NX-1510, and in the alteration of wettability the smallest contact angle was obtained by dissolving $1000 \mathrm{ppm}$ of surfactant NX-1510. Also, the results of interfacial tension tests confirm the better performances of these surfactants in formation salinity and high salinity. Additionally, a total of $72 \%$ recovery was achieved with a secondary saline water flooding and flooding with a $1000 \mathrm{ppm}$ of TR-880 surfactant.
\end{abstract}

Keywords Water injection · Surfactant · Interfacial tension (IFT) - Critical micelle concentration (CMC) - Wettability alteration $\cdot$ Contact angle

\section{Introduction}

Surfactants are known as reducing agents for water and oil interfacial tension (IFT) in chemical EOR processes. In addition, many studies have noted the alteration in the wettability of rocks to hydrophilicity by surfactants. Interfacial tension and wettability of the reservoir rock are both effective

Abbas Khaksar Manshad

khaksar@put.ac.ir; akmanshad113@gmail.com

$\triangle$ Amir H. Mohammadi amir_h_mohammadi@yahoo.com

1 Department of Petroleum Engineering, Science and Research Branch, Islamic Azad University, Tehran, Iran

2 Discipline of Chemical Engineering, School of Engineering, University of KwaZulu-Natal, Howard College Campus, King George V Avenue, Durban 4041, South Africa

3 Department of Petroleum Engineering, Abadan Faculty of Petroleum Engineering, Petroleum University of Technology (PUT), Abadan, Iran factors in any process of chemical water injection, which, by decreasing the capillary pressure, make it easy for the trapped and residue oil in the reservoirs to recover (Manshad et al. 2016, 2017a; Nowrouzi et al. 2018, 2019a, b, c). In general, it can be said that surfactants, with mechanisms such as reducing interfacial tension (Hezave et al. 2013a), wettability alteration (Salehi et al. 2008), creating emulsions (Sheng 2010) and forming foam (Emadi et al. 2017, 2019; Amirsadat et al. 2017), increase oil production during the process of flooding. The strength of each of these mechanisms depends on the nature and composition of surfactants, such as ionic charge, basic fluid characteristics such as salinity and dissolved ion types, temperature and pressure, and reservoir fluid composition (Austad and Milter 1997). Often in a surfactant injection project, factors such as high salinity performance because of the presence of formation salinity in the reservoir have particular importance, so it seems reasonable to try to use materials that have a good saline performance. Another noteworthy point in the injection of surfactants is the critical micelle concentration 
(CMC). Surfactants at this concentration normally have the best efficiency in reducing interfacial tension. Additionally, surfactants are usually expensive materials; therefore, the use of materials that have lower CMCs is more cost-effective and justifiable (Manshad et al. 2017b; Najimi et al. 2019; Nowrouzi et al. 2020a). A large number of laboratory studies have been carried out in recent years to measure the efficacy of various surfactants in the development of oil extraction. Rostami et al. used an amino acid surfactant for this purpose. They demonstrated, with interfacial tension, wettability and core flooding tests, that the surfactant used in reducing the interfacial tension and the alteration in wettability yielded a $12 \%$ recovery in the tertiary injection (Rostami et al. 2017). Hezave et al. (2013b) used an ionic liquid $\left[\mathrm{C}_{12} \mathrm{mim}\right][\mathrm{Cl}]$ as a surfactant. Their results show a very low interfacial tension and CMC with less absorption than conventional surfactants. $\mathrm{Pal}$ et al. with the design and synthesis of a coconut oilbased anionic surfactant investigated their effect on EOR. Their results, in addition to ultra-low interfacial tension, show moderate wettability, suitable temperature stability and improved recovery by surfactant in the presence of polymer (Pal et al. 2018a). Kumar and Mandal synthesized and used a group of carboxybetaine-based surfactants with 12-, 14-, 16- and 18-carbon hydrophobic tails. They observed a greater reduction in interfacial tension by increasing the number of carbons in the hydrophobic tail. In addition, they were able to produce $30.82 \%$ of the original oil in the sand plug by flooding a small amount of surfactant with alkali and polymer (Kumar and Mandal 2018). Yan et al. reviewed a new series of double-chain single-head nonionic surfactants in the surfactant-polymer flooding process. The formation of a stable emulsion, ultra-low interfacial tension in the range of $10^{-3}-10^{-4} \mathrm{mN} / \mathrm{m}$, and the alteration of the sandstone wettability toward the hydrophilicity are of the results they found (Yan et al. 2017). Somewhere else, they improved the results with the binary combination of these surfactants (Yan et al. 2018). Kumar et al. examined the ability of cationic surfactants from the $\mathrm{C}_{n} \mathrm{TAB}$ family to reduce interfacial tension and wettability. Their results indicate that $\mathrm{C}_{15} \mathrm{TAB}$ and $\mathrm{C}_{19} \mathrm{TAB}$ have a better ability to reduce the interfacial tension of $\mathrm{C}_{10} \mathrm{TAB}$ and $\mathrm{C}_{16} \mathrm{TAB}$ (Kumar et al. 2016). Hajibagheri et al. investigated the effect of the combination of solutions of a chemical surfactant and a biosurfactant produced from bacteria. They indicated that wettability alteration to hydrophilicity by using biosurfactant, while adding SDBS to this process, is harmful. But in reducing IFT, the combination of these two is more effective than using the biosurfactant and SDBS as a one-dimensional one. They eventually considered biosurfactants produced by bacteria more effective (Hajibagheri et al. 2018). Ahmadi and Shadizadeh used the Ziziphus leaf extract as a natural surfactant. Reduced interfacial tension and high oil recoveries are evident in their results, but this natural surfactant has higher adsorption and
CMC than ionic liquids and chemical surfactants (Ahmadi and Shadizadeh 2013). Kumar et al. investigated the application of Jatropha oil-synthesized surfactants in increasing oil recoveries. Using this surfactant, they reported an ultra-low interfacial tension of $0.0917 \mathrm{mN} / \mathrm{m}$ at a concentration of $\mathrm{CMC}$ and $0.00108 \mathrm{mN} / \mathrm{m}$ in the presence of optimal salinity. In addition, the synthesized surfactant has the ability to alter the wettability of the quartz surface from oleophilic to hydrophilic (Kumar et al. 2017). Pal et al. synthesized a series of Gemini surfactants. Their observations on interfacial tension yield very low values of about $10^{-2}-10^{-3} \mathrm{mN} / \mathrm{m}$, and in contact angle measurements, it shows wettability alteration to hydrophilicity (Pal et al. 2018b). Takassi et al. (2017) synthesized an amino acid-based surfactant and investigated its effect on interfacial tension and carbonate rock wettability alteration and reduced $38.53 \%$ in interfacial tension water-kerosene and decreased $17.76 \%$ at contact angles. One of the challenges of using surfactants is their poor performances in the very high salinity of the reservoir, and researches on the surfactants that are effective and even better in this condition are still rare. Different kinds of surfactants are used as an additive to the injected water to strengthen it based on various types of mechanisms. Commercial surfactants are the types of surfactants that are most commonly used in the detergent industry. Their detergence, like any other surfactant, is due to their dual structure. The pendant drop IFT and contact angle tests were investigated. In addition, the effects of high temperature, pressure and high salinity were also studied using a water-based solution and a saline solution with high concentrations of $\mathrm{NaCl}$ and $\mathrm{KCl}$. At the end of the experiment, the core flooding was tested with saline water and a fluid containing the optimal surfactant for minimal interfacial tension to obtain oil recovery. The innovation of this research is to use and investigate effective surfactants in high salinity, suitable for reservoir conditions.

\section{Materials and equipment}

\section{Surfactants}

Surfactants AN-120, NX-1510 and TR-880 were designed, synthesized and used. Table 1 shows the characteristics of these surfactants.

\section{Crude oil and rock samples}

Dead crude oil was extracted from Sarvestan oilfield located in central Iran with API equivalent to 29, and the specifications given in Table 2 were used. The samples taken from Asmari carbonate formation outcrop in the southwest of Iran were used as a cylindrical plug and narrow sections. The 
Table 1 Specifications of surfactants used in this study

\begin{tabular}{|c|c|c|}
\hline $\begin{array}{l}\text { Commercial } \\
\text { name }\end{array}$ & Structure & $\begin{array}{c}\text { Average molecular } \\
\text { weight }(\mathrm{g} / \mathrm{mol})\end{array}$ \\
\hline AN-120 & dodecylbenzene sulfonic acid + nonylphenolethoxylate & 490 \\
\hline NX-1510 & $\begin{array}{c}\mathrm{CH}_{12} \mathrm{H}_{25}-\mathrm{N}_{\mathrm{N}_{3}^{+}}^{\mathrm{CH}_{3}}-\mathrm{CH}_{2}-\mathrm{COO}^{-} \\
\text {dodecyl dimethyl amine betaine }+ \text { octadecyl amine } \\
\text { ethoxylate }\end{array}$ & 600 \\
\hline TR -880 & 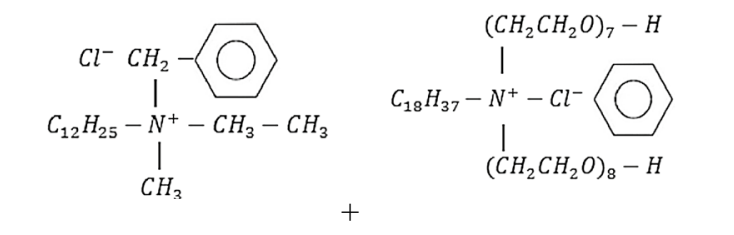 & 680 \\
\hline
\end{tabular}

Table 2 Crude oil components

\begin{tabular}{ll}
\hline Hydrocarbons & Percent \\
\hline Propane & - \\
$i$-Butane & - \\
$n$-Butane & 4.59 \\
$i$-Pentane & 11.66 \\
$n$-Pentane & 18.92 \\
2-Methyl pentane & 16.28 \\
3-Methyl pentane & 7.45 \\
$n$-Hexane & 19.47 \\
Methylcyclopentane & 8.12 \\
Benzene & 5.18 \\
Cyclopentane & 1.46 \\
1,1-Dimethylcyclopentane & 5.06 \\
Other isomers & 1.81 \\
Total & 100.00
\end{tabular}

rock contains $61 \%$ dolomite and $39 \%$ calcite, and its XRD analysis is shown in Fig. 1.

\section{Brine and salts}

The water from the Sarvestan reservoir and solutions from the dissolution of $\mathrm{NaCl}$ and $\mathrm{KCl}$ salts with a purity greater than 99\%, purchased from MP Biomedicals in the Netherlands, were used as saline water. Table 3 shows the analysis of formation water.

\section{Nitrogen, toluene and acetone}

Nitrogen gas supplied by Abughaddareh Industrial Gases Co. Iran, with a purity of $99.99 \%$, with a primary pressure of 400 psi, and toluene and acetone purchased from MP Biomedical, the Netherlands, had a purity higher than $99.9 \%$.

\section{Interfacial tension and contact angle apparatus}

Interfacial tension and contact angle equipment by Fars EOR Co., the IFT400 brand, was used to conduct interfacial tension and contact angle tests in this study. This device based on the pendant drop calculates the interfacial tension between two immiscible fluids. Two syringes connected to rotary knobs, in addition to bulk and drop fluid storage, which also make pressure adjustable, a cell with three thermal elements and two glass valves, one against the adjustable lighting bar and the other against a 2 megapixel CCD HD camera as a drip chamber, are used; in addition, the device is equipped with a marker and a temperature and pressure controller, high-pressure valves, 2.05-mm-diameter droplet needle and a computer equipped with software. A pressure tolerance of up to $3000 \mathrm{psi}$ with a precision of $0.5 \%$ full scale, a maximum allowed temperature of up to $453.15 \mathrm{~K}$ with an uncertainty of \pm 0.3 , and an IFT uncertainty of $0.2-0.5 \mathrm{mN} / \mathrm{m}$ can be calculated using the IFT400 device. Drop cell is filled by a special pump that is rotated by the user from a transparent bulk liquid, and the oil droplet is pushed by a mutual pump in the bulk fluid from the tip of the nozzle, which is embedded in the tests of this study below the compartment. The camera gives the pictures 
Fig. 1 XRD analysis of the used carbonate rock
Table 3 Formation water composition

of the droplet to the software, and the software uses Eq. (1) and information, such as the density of two immiscible fluids, gravity, temperature and pressure that the user enters, reports the interfacial tension at every moment:

$\gamma=\frac{\Delta \rho g D^{\prime 2}}{H}$,

\begin{tabular}{lc}
\hline Ion & $\begin{array}{c}\text { Concentra- } \\
\text { tion (ppm) }\end{array}$ \\
\hline $\mathrm{Na}^{+}$ & 22,356 \\
$\mathrm{Ca}^{2+}$ & 5200 \\
$\mathrm{Mg}^{2+}$ & 1400 \\
$\mathrm{Cl}^{-}$ & 34,506 \\
$\mathrm{SO}_{4}{ }^{2-}$ & 95 \\
$\mathrm{HCO}_{3}{ }^{-}$ & 67 \\
$\mathrm{TDS}$ & 62,000 \\
$\mathrm{TH}$ & 6600 \\
\hline
\end{tabular}

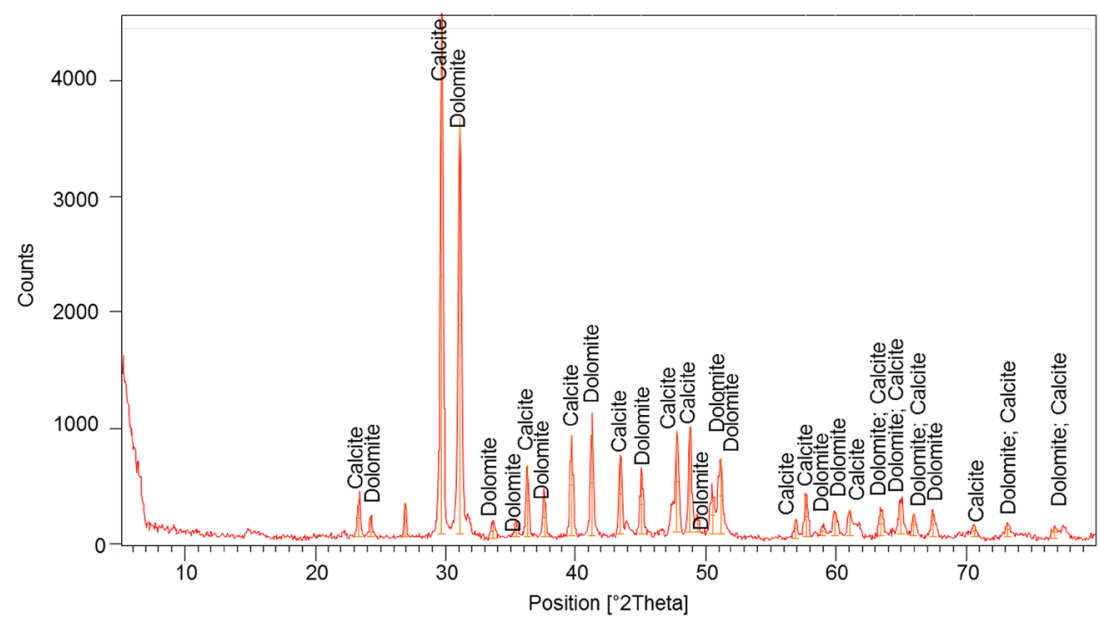

where $\Delta \rho$ is the difference in the density of the droplet and bulk fluid $\left(\mathrm{g} / \mathrm{cm}^{3}\right), g$ is the gravitational acceleration of the Earth $\left(\mathrm{cm} / \mathrm{s}^{2}\right), D^{\prime}$ is the large diameter of the droplet $(\mathrm{cm})$ and $H$ is the droplet shape factor which is a function of $S=d / D$ where $d$ is the horizontal diameter calculated at a distance $D$ above the droplet.

The required heat is supplied by three thermal elements, and a PT-100 thermometer controls its temperature after optimizing the parameters of the PID controller. The device must be well washed before and after each test with solvents like toluene, acetone and water and dried with nitrogen gas. The accurate calculation of the device is ensured by proper washing and performing test measurements of interfacial tension for water-air and water-toluene systems, which have a certain amount. The schematic of the IFT400 is shown in Fig. 2.

\section{Core flooding apparatus}

The flooding device according to Fig. 3 of Fars EOR Co. was used. A pump pumps the hydraulic fluid automatically to the rear of the pistons in three cylinders, each containing
Fig. 2 Schematic of the interfacial tension and contact angle IFT400. 1: Bulk flow pump. 2: Adjustable light source. 3: Indicator and temperature and pressure controller. 4: High-pressure valve. 5: Cell. 6: Camera. 7: Drop needle. 8: Cell content drainage line. 9: Drop fluid pump. 10: Computer equipped with device software (Manshad et al. 2017b)

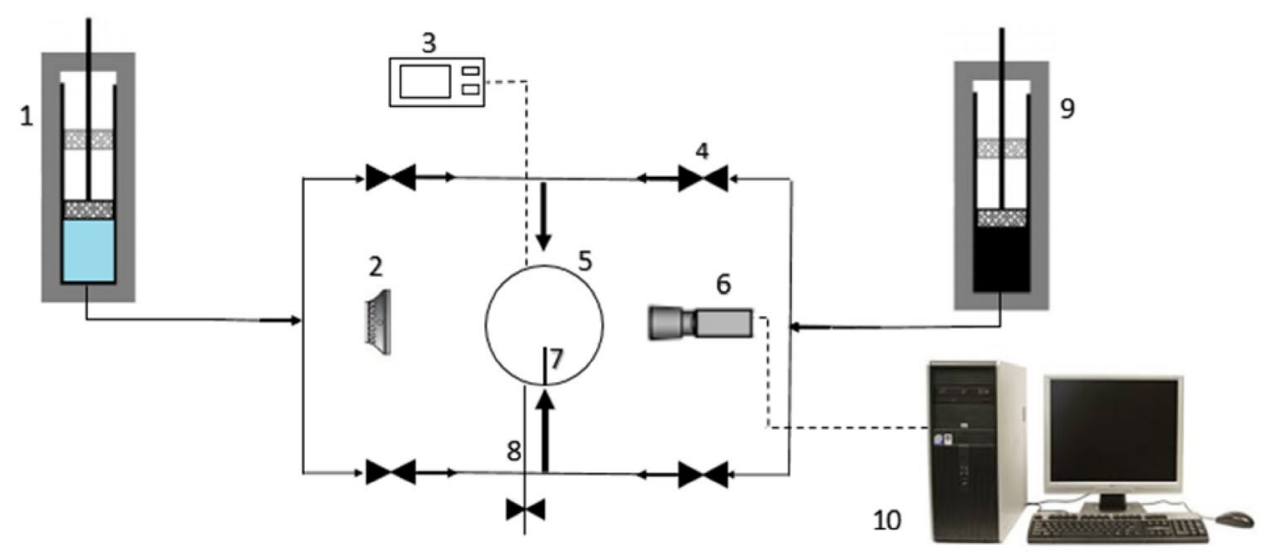


Fig. 3 Schematic of the core flooding device. 1: HPLC pump. 2: Barometer. 3: Valve. 4: Cylinder containing crude oil. 5: Saline water containing cylinder. 6: Cylinder containing surfactant solution. 7: Core holder chamber. 8: Fluid flow distributor. 9: Core. 10: Blocking rubber around the core. 11: Oven. 12: Manual hydraulic pump. 13: Outlet fluid collecting vessel

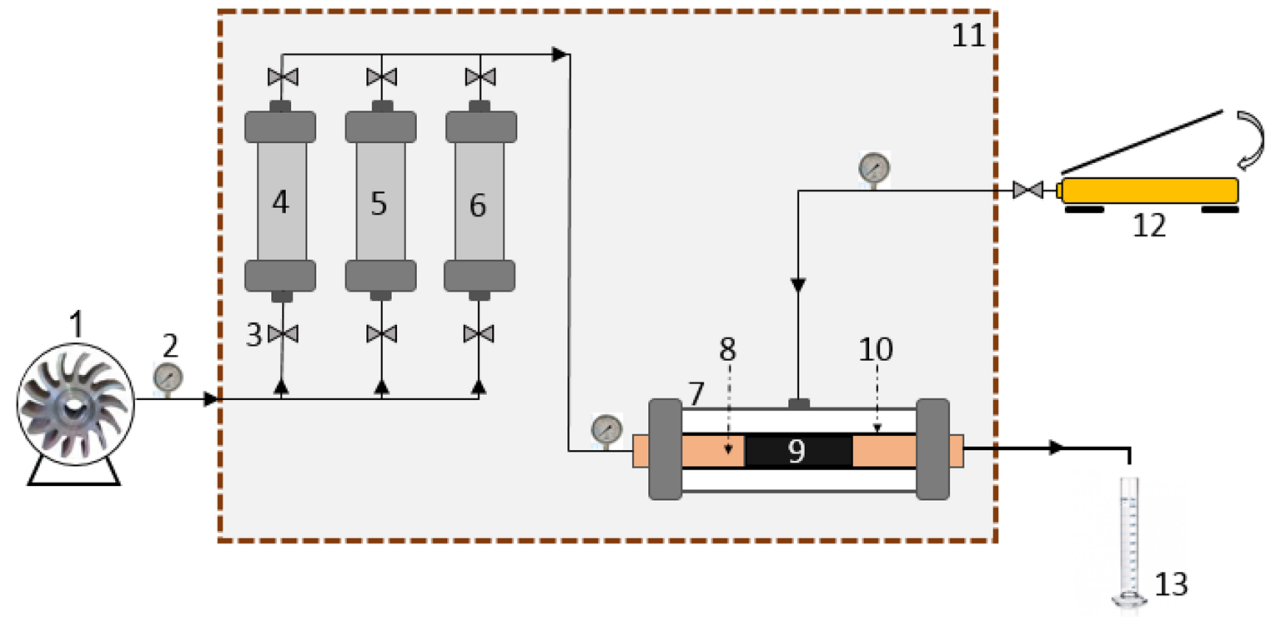

a special fluid. The selected fluid in the cylinder is inserted into the core holder chamber and injected into the core with the rate or input pressure chosen by the user. The core holder chamber itself consists of two parts of the flow of fluid through its inlet and outlet, and a special rubber to block around the one-and-a-half-inch plug, which is pumped by a hydraulic fluid pump manually to the core holder and compresses it around the plug and blocks the flow from passing around the plug. Cylinders containing oil, saline water and surfactant solutions are located along with a core holder inside an oven to apply the temperature to the system. The output line of the core holder chamber is removed from the oven, and the outlet fluid is stored in a special fluid collection vessel.

\section{Experimental procedure}

The interfacial tension tests after the preparation of solutions of surfactants AN-120, NX-1510 and TR-880 were performed at concentrations of 0, 100, 500, 1000, 3000, 5000 and $7000 \mathrm{ppm}$ with distilled water and formation water base at a reservoir temperature of $351.15 \mathrm{~K}$ and the $14.7 \mathrm{psi}$ pressure using the IFT400 device which was described earlier. Subsequently, the salinity effects of $\mathrm{NaCl}$ at 150,000 , 200,000 and $250,000 \mathrm{ppm}$ were studied to investigate the effect of high salinity on the performances of surfactants at $351.15 \mathrm{~K}$ and $14.7 \mathrm{psi}$. The effects of temperature and pressure on the interfacial tension of surfactant solutions and crude were studied at a constant concentration of $500 \mathrm{ppm}$ of each surfactant dissolved in $150,000 \mathrm{ppm} \mathrm{KCl}$ salt at 303.15 , 333.15 and $353.15 \mathrm{~K}$, and pressures of 14.7, 1000, 1500 and $2000 \mathrm{psi}$. To investigate the alteration of carbonate rock wettability, the carbonate sections were cut. Then, the cross sections were polished with glazing-free china. After removal of the produced dirt by the high-pressure nitrogen gas, they remained in toluene for 1 day to eliminate the fatty acids resulting from contact with the hands. After that, they dried up in the crude oil of the sample at $343.15 \mathrm{~K}$ for 12 days to obtain the initial oleophilicity (Manshad et al. 2017a; Nowrouzi et al. 2019d, 2020b). The contact angle experiments for oil droplets on aged carbonate sections in surfactant solutions at concentrations of 100,500 and $1000 \mathrm{ppm}$ with formation water base were carried out, and the aging with the oil column was performed for 3 days at $351.15 \mathrm{~K}$ and 14.7 psi. Eventually, the flooding test was performed to investigate the uptake of oil from saturated carbonate core. The flooding test with TR- 880 solution as the optimum solution was performed to reduce the interfacial tension in the critical micelle concentration at $351.15 \mathrm{~K}$ at a rate of $0.5 \mathrm{cc} /$ min before the secondary flooding water was formed at this temperature.

\section{Results and discussion}

\section{Interfacial tension}

Table 4 shows the interfacial tension values of surfactant solutions of AN-120, NX-1510 and TR-880 at different concentrations with the distilled water and formation water base and crude oil at $351.15 \mathrm{~K}$ and $14.7 \mathrm{psi}$ pressure. The values of this table are the equilibrium interfacial tension, which is recorded in interfacial tension experiments after giving a sufficient amount of time to achieve the balance of the droplet and bulk system. Figures 4 and 5 show information of this table for distilled water and formation water-based solutions, respectively. Figures 6, 7 and 8 correspond, respectively, to dynamic interfacial tension values of AN-120, NX-1510 and TR-880 surfactant solutions at various concentrations of formation water base and crude oil, and interfacial tension changes against time at the temperature of $351.15 \mathrm{~K}$ and the pressure of $14.7 \mathrm{psi}$. Table 5 shows the high salinity effects resulting from the dissolution of $\mathrm{NaCl}$ salt at concentrations of $150,000,200,000$ and $250,000 \mathrm{ppm}$ on the interfacial 
Table 4 Interfacial tension values of solutions containing AN-120, NX-1510 and TR-880 surfactants with different concentrations and crude oil at $351.15 \mathrm{~K}$ and $14.7 \mathrm{psi}$

\begin{tabular}{lccc}
\hline Surfactant concentration $(\mathrm{ppm})$ & \multicolumn{3}{l}{ Interfacial tension $(\mathrm{mN} / \mathrm{m})$ (formation brine) } \\
\cline { 2 - 4 } & AN-120 & NX-1510 & TR-880 \\
\hline 0 & 26.32 & 26.32 & 26.32 \\
100 & 12.64 & 10.11 & 5.87 \\
500 & 4.09 & 4.62 & 1.88 \\
1000 & 3.00 & 3.26 & 1.27 \\
3000 & 3.38 & 2.45 & 1.12 \\
5000 & 3.67 & 2.41 & 1.19 \\
7000 & 3.71 & 2.46 & 1.09 \\
\hline Surfactant concentration $(\mathrm{ppm})$ & Interfacial tension (mN/m) (distilled water) & \\
\cline { 2 - 4 } & AN-120 & NX-1510 & \\
\hline 0 & 27.55 & 27.55 & 12.16 \\
100 & 16.11 & 14.76 & 6.41 \\
500 & 14.53 & 6.82 & 4.25 \\
1000 & 12.33 & 3.50 & 3.75 \\
3000 & 5.49 & 3.46 & 3.38 \\
7000 & 4.92 & 3.61 & 5.43 \\
\hline
\end{tabular}

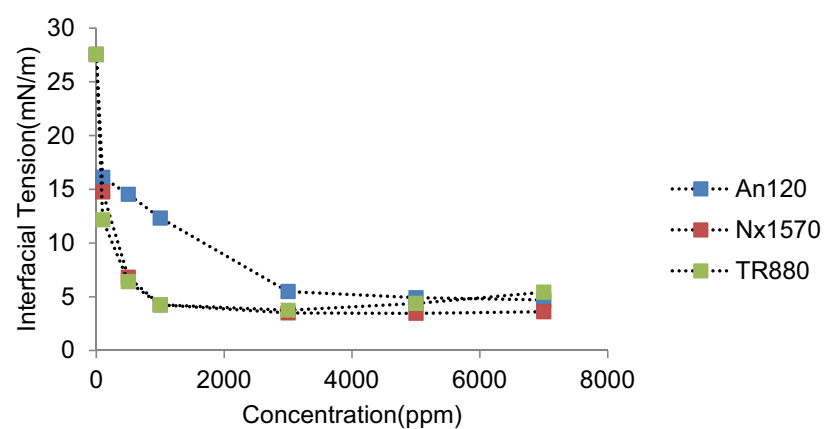

Fig. 4 Interfacial tension curves of surfactant solutions at different concentrations with distilled water base and crude oil at $351.15 \mathrm{~K}$ and pressure of $14.7 \mathrm{psi}$

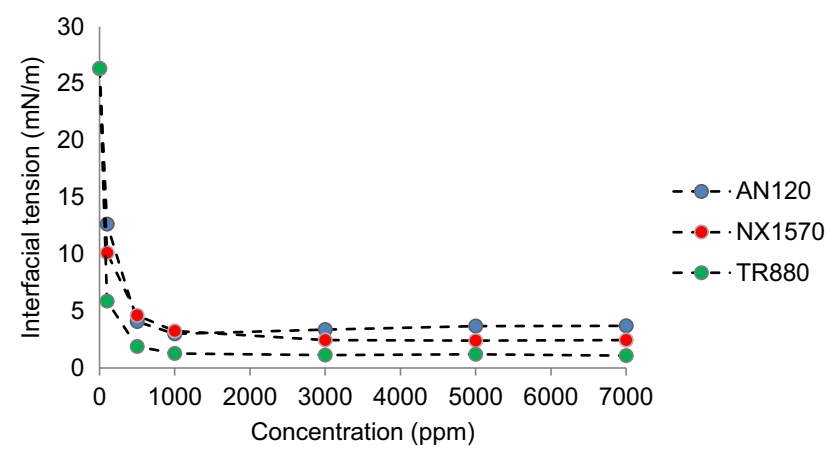

Fig. 5 Interfacial tension curves of surfactant solutions at different concentrations with formation water base and crude oil at $351.15 \mathrm{~K}$ and pressure of $14.7 \mathrm{psi}$

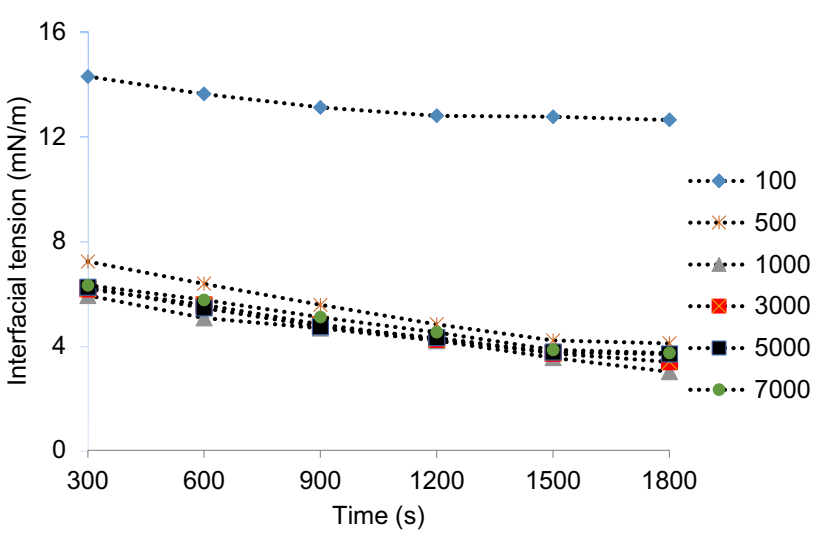

Fig. 6 Dynamic interfacial tension curves of AN-120 solution at various concentrations with formation water base and crude oil at $351.15 \mathrm{~K}$ and pressure of $14.7 \mathrm{psi}$

tension of surfactant solutions and crude oil at $351.15 \mathrm{~K}$ and 14.7 psi. In addition, Figs. 9 and 10 show interfacial tension variations over time for solutions of 25 and $50 \mathrm{ppm}$ of TR-880 surfactant and 150,000, 200,000 and 250,000 ppm of $\mathrm{NaCl}$ salt. The effect of pressure and temperature on the interfacial tension of surfactant solutions and crude oil is shown in Table 6. The salinity of the solutions in the tests of this table is $150,000 \mathrm{ppm} \mathrm{KCl}$ and $500 \mathrm{ppm}$ of $\mathrm{AN}-120$, NX-1510 and TR-880 surfactants.

The results of Table 4 show that CMC is $3000 \mathrm{ppm}$ for solutions of surfactants AN-120, NX-1510 and TR-880 when distilled water is used as a base fluid. The interfacial 


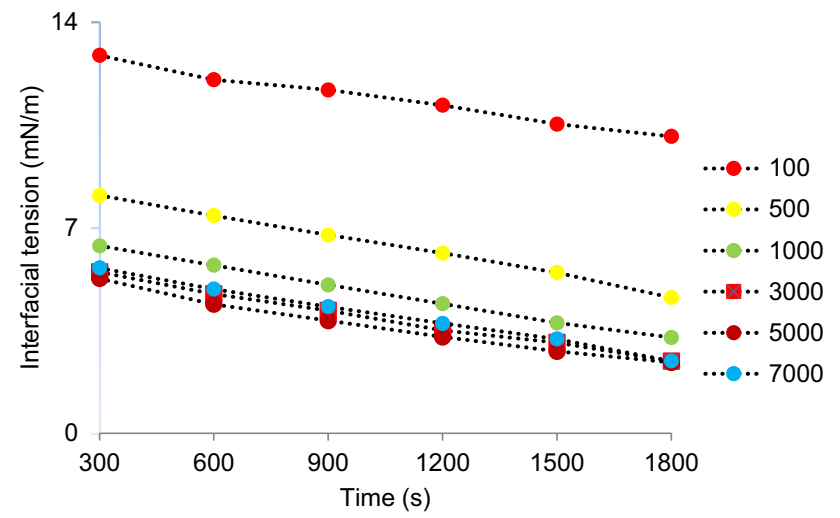

Fig. 7 Dynamic interfacial tension curves of NX-1510 solution at various concentrations with formation water base and crude oil at $351.15 \mathrm{~K}$ and pressure of $14.7 \mathrm{psi}$

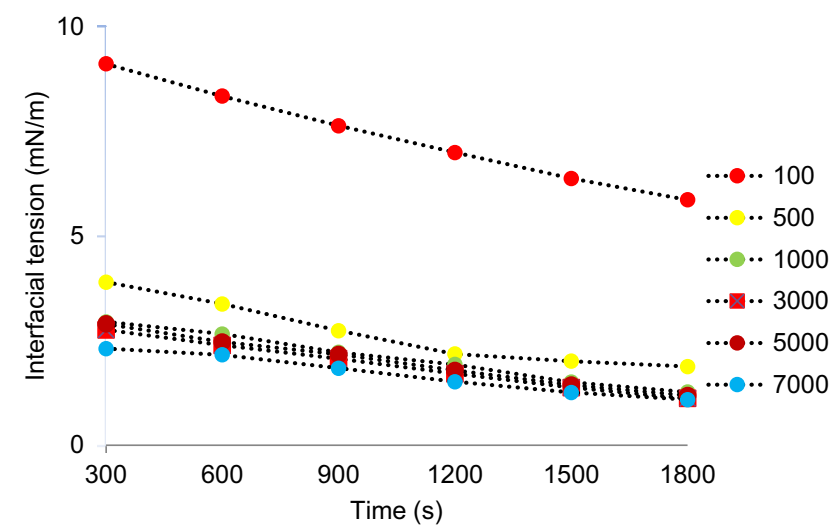

Fig. 8 Dynamic interfacial tension curves of TR-880 solution at various concentrations with formation water base and crude oil at $351.15 \mathrm{~K}$ and pressure of $14.7 \mathrm{psi}$ tension values at this concentration are equal to 5.49, 3.50 and $3.75 \mathrm{mN} / \mathrm{m}$ at a temperature of $351.15 \mathrm{~K}$ and a pressure of 14.7 psi. Meanwhile, CMC is 1000 ppm for all three surfactants dissolved in saline water. In addition, the recorded interfacial tension values for AN-120, NX-1510 and TR-880 surfactants are numerically equal to $3.00,3.26$ and $1.27 \mathrm{mN} / \mathrm{m}$, respectively. The lowest recorded interfacial tension of the TR-880 surfactant solution at $1000 \mathrm{ppm}$ with a water-based base is $1.27 \mathrm{mN} / \mathrm{m}$. The reduction in CMC and the amount of interfacial tension in this concentration indicates the better performance of these surfactants in salinity equivalent to formation salinity. However, in the rest of the concentrations, a significant reduction in the values of interfacial tension while using the saline water compared to salinity free water is evident. The graphs in Figs. 6, 7 and 8 relating to the dynamic interfacial values of the surfactant solutions show the decreasing trend of interfacial tension with time. The overall comparison of these graphs shows that, in addition to the dependence of the interfacial tension to time, the concentration of surfactant is also an important factor in reducing interfacial tension, and in all cases, it decreases with increasing interfacial tension concentration. The passage of time is needed in IFT experiments, and short-term data are not reliable (Putra and Hakiki 2019). Experimental models have been suggested for the study of dynamic IFT and equilibrium time. Equations of these models depend on the factors affecting IFT. In general, three important factors such as surfactant concentration, type and concentration of ions are effective in the change of the water-oil IFT. These factors control the release of surfactant molecules from the aqueous solution to the oil through the interface (Lashkarbolooki and Ayatollahi 2017). Equation (2) shows this release (Lashkarbolooki et al. 2016a, b):

$\gamma_{t}=\gamma_{0}-2 R T C \sqrt{\frac{3 D t}{7 \pi}}$
Table 5 Interfacial tension values of AN-120, NX-1510 and TR-880 surfactant solutions at different concentrations with $\mathrm{NaCl}$ solution in high concentrations and crude oil in $\mathrm{mN} / \mathrm{m}$ at $351.15 \mathrm{~K}$ and pressure of $14.7 \mathrm{psi}$

\begin{tabular}{|c|c|c|c|c|c|c|c|c|}
\hline $\begin{array}{l}\mathrm{NaCl} \text { concentra- } \\
\text { tion }(\mathrm{ppm})\end{array}$ & 0 & 25 & 50 & 100 & 250 & 500 & 750 & 1000 \\
\hline \multicolumn{9}{|c|}{ TR-880 concentration (ppm) } \\
\hline 250,000 & 14.69 & 5.87 & 4.76 & 3.81 & 1.25 & 0.86 & 0.79 & 0.68 \\
\hline 200,000 & 15.38 & 6.82 & 5.22 & 4.23 & 1.56 & 0.97 & 0.83 & 0.76 \\
\hline 150,000 & 18.08 & 8.55 & 5.53 & 4.59 & 2.43 & 1.07 & 0.88 & 0.85 \\
\hline \multicolumn{9}{|c|}{ NX-1570 concentration (ppm) } \\
\hline 250,000 & 14.69 & 5.81 & 4.19 & 3.23 & 1.36 & 1.21 & 1.09 & 1.01 \\
\hline 200,000 & 15.38 & 6.66 & 5.54 & 4.34 & 2.41 & 1.39 & 1.18 & 1.14 \\
\hline 150,000 & 18.08 & 9.87 & 6.88 & 4.62 & 3.01 & 1.64 & 1.40 & 1.35 \\
\hline \multicolumn{9}{|c|}{ AN-120 concentration (ppm) } \\
\hline 250,000 & 14.69 & 6.39 & 4.43 & 2.13 & 1.37 & 1.00 & 0.95 & 0.98 \\
\hline 200,000 & 15.38 & 8.12 & 6.34 & 2.56 & 1.63 & 1.07 & 1.04 & 1.20 \\
\hline 150,000 & 18.08 & 12.05 & 10.61 & 8.77 & 3.40 & 2.33 & 1.31 & 1.66 \\
\hline
\end{tabular}




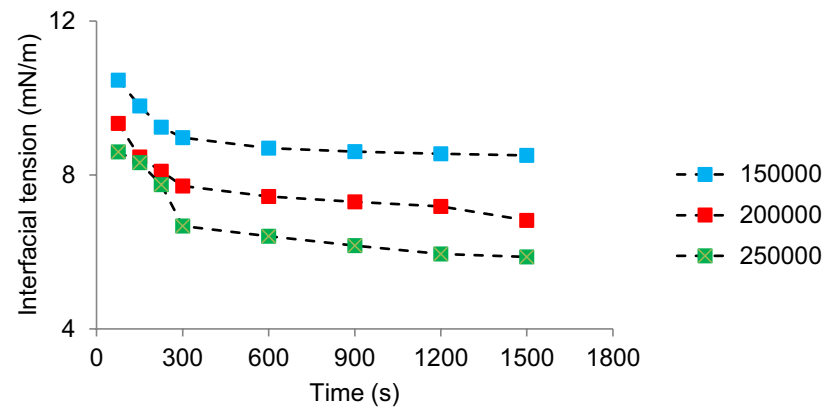

Fig. 9 Dynamic interfacial tension curves of TR- 880 solution at a concentration of $25 \mathrm{ppm}$ and salinity from $\mathrm{NaCl}$ dissolution at various concentrations at $351.15 \mathrm{~K}$ and $14.7 \mathrm{psi}$

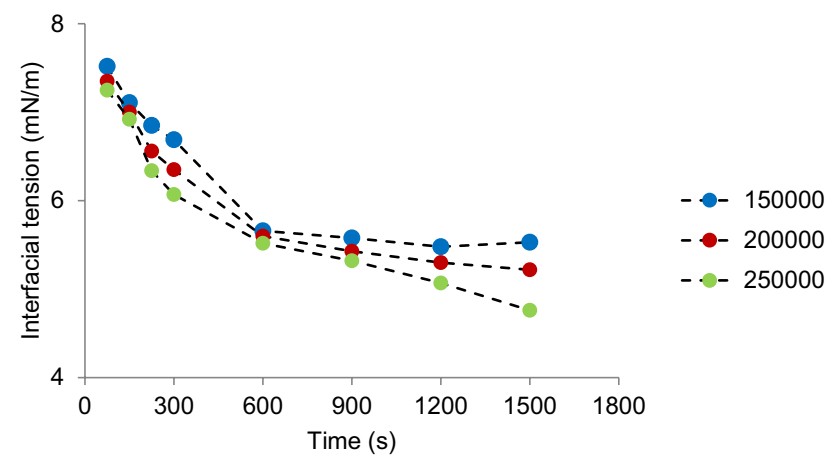

Fig. 10 Dynamic interfacial tension curves of TR-880 solution at a concentration of $50 \mathrm{ppm}$ and salinity from $\mathrm{NaCl}$ dissolution at various concentrations at $351.15 \mathrm{~K}$ and $14.7 \mathrm{psi}$

Table 6 Effect of temperature and pressure variations on the interfacial tensions of AN-120, NX-1510 and TR-880 surfactants in a concentration of $500 \mathrm{ppm}$ and $\mathrm{KCl}$ at $150,000 \mathrm{ppm}$ with crude oil

\begin{tabular}{lllll}
\hline Temperature (K) & Pressure (psi) & \multicolumn{3}{c}{ Interfacial tension $(\mathrm{mN} / \mathrm{m})$} \\
\cline { 3 - 5 } & & 1.48 & 1.38 & 1.04 \\
\cline { 3 - 5 } 303.15 & 14.7 & 1.55 & 1.41 & 1.01 \\
& 1000 & 1.59 & 1.44 & 0.98 \\
& 1500 & 1.61 & 1.47 & 0.91 \\
333.15 & 2000 & 1.57 & 1.54 & 1.09 \\
& 14.7 & 1.49 & 1.58 & 1.07 \\
& 1000 & 1.60 & 1.69 & 1.00 \\
353.15 & 1500 & 1.64 & 1.74 & 0.99 \\
& 2000 & 1.63 & 2.00 & 1.24 \\
& 14.7 & 1.95 & 2.10 & 1.19 \\
& 1000 & 1.83 & 2.01 & 1.13 \\
& 1500 & 1.80 & 1.97 & 1.10 \\
\hline
\end{tabular}

where $R$ is the global gas constant equal to $8.314 \mathrm{~J} / \mathrm{mol} \mathrm{K}, T$ is the temperature in $\mathrm{K}, D$ is the diffusivity $\left(\mathrm{m}^{2} / \mathrm{s}\right), t$ is a time in seconds, $C$ is the concentration of surfactant $\left(\mathrm{mol} \mathrm{m}^{-3}\right)$, $\gamma_{t}$ is IFT at time $t$ and $\gamma_{0}$ is IFT at $t=0$.

Equation (2) is used as the short-time equation at the beginning of the adsorption process, while the adsorption process is shown near the equilibrium with the long-time Eq. (3) (Xu 2005; Kumar 2012; Zarkar et al. 2015):

$\gamma_{t}=\gamma_{\mathrm{e}}+\frac{R T \Gamma_{\mathrm{eq}}^{2}}{C} \sqrt{\frac{7 \pi}{12 D t}}$,

where $\gamma_{\mathrm{e}}$ is the equilibrium IFT, $\Gamma_{\text {eq }}$ is the equilibrium surface excess concentration, $\gamma_{0}$ and $\gamma_{\mathrm{e}}$ are obtained by IFT intercept versus $t^{1 / 2}$ and $t^{-1 / 2}$, respectively.

Equations (2) and (3) are expected to be less reliable by increasing time with reduced time, respectively (Joos et al. 1992). The easiest way to estimate the equilibrium time is obtained from Eq. (4) (Kumar 2012; Jeribi et al. 2002):

$\gamma_{t}=\gamma_{\mathrm{e}}+\left(\gamma_{0}-\gamma_{\mathrm{e}}\right) \mathrm{e}^{\frac{-t}{\tau}}$

where $\tau$ is the time of absorption.

Based on this equation, with increasing dependence and concentration of active substances, the time of absorption and reaching the equilibrium zone decreases. In addition, the empirical Eq. (5) also has a high ability to describe IFT behavior (Hua and Rosen 1988, 1991):

$\frac{\left(\gamma_{0}-\gamma_{t}\right)}{\left(\gamma_{t}-\gamma_{\mathrm{e}}\right)}=\left(\frac{t}{t^{*}}\right)^{n}$,

where $n$ and $t^{*}$ are constants, and their values depend on the nature of the surfactant and can be calculated by converting the equation to its linear form (Lashkarbolooki and Ayatollahi 2017):

$\log \frac{\left(\gamma_{0}-\gamma_{t}\right)}{\left(\gamma_{t}-\gamma_{\mathrm{e}}\right)}=n \log t-n \log t^{*}$

The efficacy of surfactants in high salinity is also confirmed when a base fluid is mixed with $\mathrm{NaCl}$ at high concentrations of 150,000, 200,000 and 250,000 ppm (Table 5). For example, for AN-120 surfactant solution at concentrations of $0,25,50,100,250,500,750$ and $1000 \mathrm{ppm}$, and $\mathrm{NaCl}$ at 250,000 ppm, the amounts of $14.69,5.87,5.53,4.76,3.81,1.25,0.86,0.79$ and $0.68 \mathrm{mN} / \mathrm{m}$ at a temperature of $351.15 \mathrm{~K}$ and a pressure of 14.7 psi are recorded, respectively. In addition, the graphs in Figs. 9 and 10 show a decreasing trend for the interfacial tension over time in solutions of 25 and 50 ppm of TR-880 surfactant and at concentrations of 150,000, 200,000 and 
$250,000 \mathrm{ppm} \mathrm{NaCl}$. The review of the changes in interfacial tension due to changes in pressure and temperature at a salinity of $150,000 \mathrm{ppm}$ of potassium chloride salt and a concentration of $500 \mathrm{ppm}$ of AN-120, NX-1510 and TR-880 surfactant in Table 6 shows that the values of interfacial tension with increasing temperature increase partially. For example, for surfactant TR-880 at a concentration of $500 \mathrm{ppm}$ and constant pressure of $2000 \mathrm{psi}$ at temperatures of $303.15,333.15$ and $353.15 \mathrm{~K}$, the interfacial tensions were $0.91,0.99$ and $1.10 \mathrm{mN} / \mathrm{m}$, respectively. However, there is no fixed and constant trend in interfacial tension variations.

Surfactants are normally organic compounds which have hydrophobic groups that play the role of the tail and the sequence and hydrophilic groups that play the role of the head, so they are normally dissolved in water and organic solvents. Surfactant molecules are leveled at the liquid level due to their hydrophilic-hydrophobic structure so that the hydrophilic head is dissolved in aqueous solution and the hydrophobic head avoids it. By increasing the concentration of surfactant and occupying the entire interface space by its molecules, aggregations of surfactants are caused by the absorption of the same parts of each other, which is referred to as the micelle. The formation of the micelle weakens the performance of the surfactant molecules by limiting their release (Schramm 2000; Torrealba and Johns 2017). Surfactants reduce the interfacial tension of the water and oil. When the micelles begin to form, they form a nucleus like a drop of oil and their ionic head creates an outer shell that improves the contact with water. Calculation of CMC can have two applications. First, it determines the efficiency of a surfactant and, secondly, allows the comparison of the efficacy of surfactants because the formation of the micelles at this concentration gives the ability to form an oil-soluble emulsion and, on the other hand, the lower $\mathrm{CMC}$ of a surfactant means to reach a lower interfacial tension requires a lesser amount of surfactant (Joos et al. 1992; Ward and Tordai 1946). With increasing hydrophobic length, the surfactant capacity increases to reduce IFT. In other words, longer tails are more effective at lower concentrations (Painter et al. 2009). As mentioned earlier, the IFT is reduced with increasing salinity. This trend can be explained with the mechanism of synergic effects of ions and surfactant. The negatively charged ions neutralize the positive surface charges of the cationic surfactants. This leads to the easier accumulation of surfactant molecules at the oil-aqueous solution interface, which causes more IFT reduction (Fig. 11). Thus, the obtained results in this work suggest that the commercial surfactant as chemicals is more tolerable for CEOR processes dealing with the harsh conditions of salinity.

\section{Contact angle}

Table 7 shows the results of the contact angle tests for the oil drop on aged carbonate sections in surfactant solutions at concentrations of 100, 500 and 1000 ppm, after 3 days at $351.15 \mathrm{~K}$ and $14.7 \mathrm{psi}$, respectively. Figure 12 shows the drop images on the cross section in each experiment. The size of the left, right and mean angles in Table 7 is recorded.
Fig. 11 Schematic of the synergic effect of ions and surfactants on IFT reduction at the oil/water interface (Zeinolabedini Hezave et al. 2014)

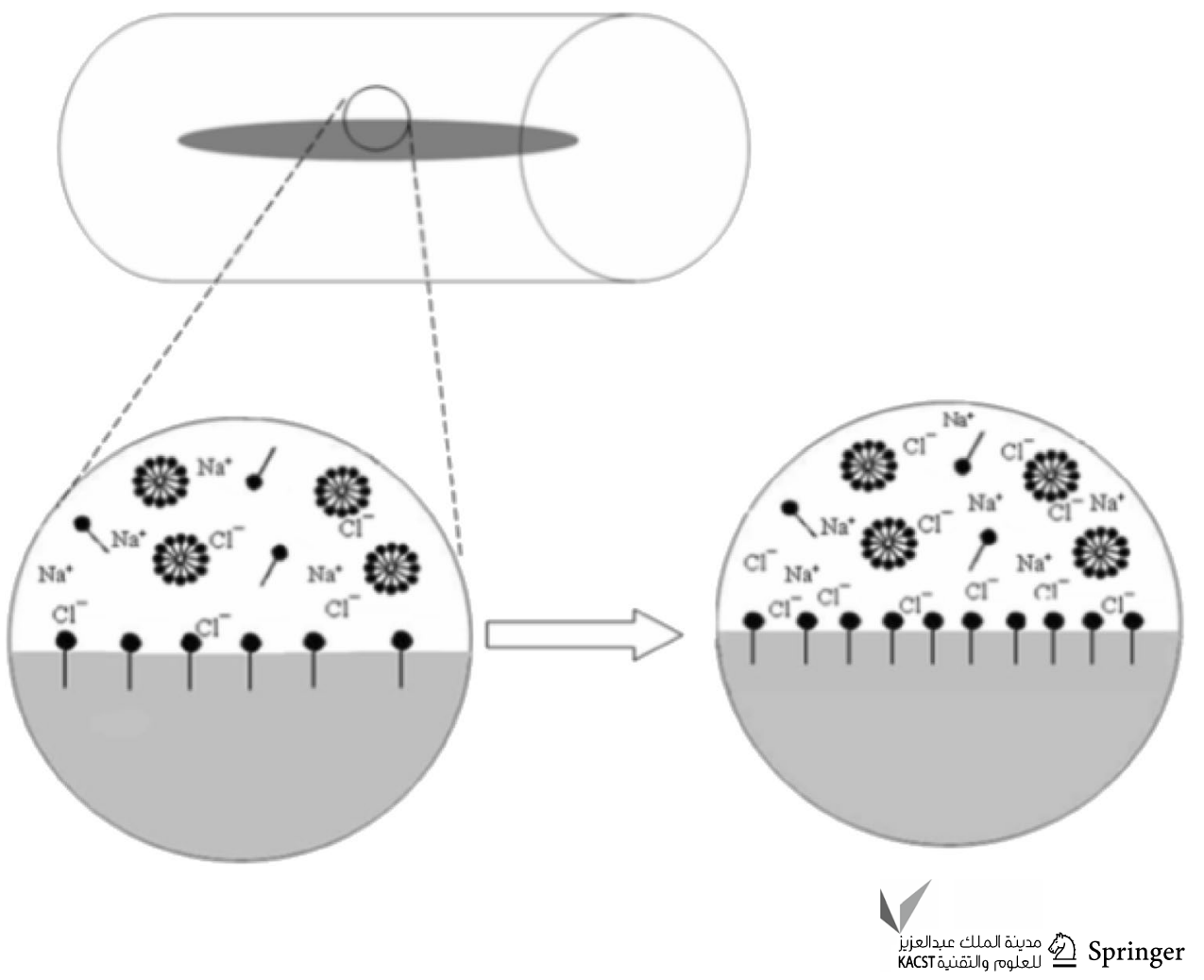


Table 7 Oil drop contact angle values for aged sections in AN-120, NX-1510 and TR-880 surfactant solutions at concentrations of 100, 500 and $1000 \mathrm{ppm}$ after 3 days at $351.15 \mathrm{~K}$ and pressure of $14.7 \mathrm{psi}$

\begin{tabular}{lllrc}
\hline No. & Concentration $(\mathrm{ppm})$ & Average angle & Left angle & Right angle \\
\hline 1 & 1000 ppm AN-120 & 38.5914 & 38.5914 & 38.5914 \\
2 & 500 ppm AN-120 & 39.2838 & 41.3836 & 37.1840 \\
3 & 100 ppm AN-120 & 40.102 & 41.8839 & 38.3201 \\
4 & 1000 ppm Nx-1510 & 27.7965 & 27.4608 & 28.1322 \\
5 & 500 ppm NX-1510 & 55.09765 & 53.6521 & 56.5432 \\
6 & 100 ppm NX-1510 & 76.68035 & 76.1298 & 77.2309 \\
7 & 1000 ppm TR-880 & 43.39845 & 44.1247 & 42.6722 \\
8 & 500 ppm TR-880 & 88.3578 & 89.9439 & 86.7717 \\
9 & 100 ppm TR-880 & 105.4511 & 107.4460 & 103.4562 \\
\hline
\end{tabular}

The data from this table show that all of the AN-120, NX-1510 and TR-880 surfactants have a good ability to reduce the contact angle and alter the carbonate rock's wettability toward the hydrophilic. Reducing the contact angle at constant temperature and pressure is correlated with the concentration of surfactants. As the surfactant concentration increases, a greater reduction in the angle of contact is observed. In the case of aged sections in AN-120 solution, at concentrations of 100,500 and 1000 ppm, the mean contact angles at $351.15 \mathrm{~K}$ and $14.7 \mathrm{psi}$ were $40.1020^{\circ}, 39.2838^{\circ}$ and $38.5914^{\circ}$, respectively. These values for NX-1510 solutions were $76.68035^{\circ}, 55.09765^{\circ}$ and $27.7965^{\circ}$, respectively, and for solutions containing TR-880, values of $105.4511^{\circ}$, $88.3578^{\circ}$ and $43.39845^{\circ}$ were obtained, respectively. It is clear that the value obtained from the contact angle test and the wettability alteration with the NX-1510 surfactant at a concentration of $1000 \mathrm{ppm}$ shows the lowest value.

Two mechanisms are generally accepted for the alteration of wettability by surfactant solutions: the creation of a stable thin film by surfactant on the surface (Salathiel 1973) and the orientation of surfactant molecules at the surface (Spinler et al. 2000). When a thin film of water is stable, oil is spread like a ball in the middle of large pores and water between oil and rock. This thin film becomes unstable due to the absorption of surfactant molecules, but the instability of a thin film of water in the site creates a continuous oil bed pathway for oil displacement, resulting in the formation of mixed wettability (Spinler et al. 2000). In other words, the continuous emission and absorption of surfactant molecules into the environment change the physical-chemical properties of the rock, resulting in a continuous pathway for the production of oil (Salathiel 1973; Ayirala et al. 2006; Jadhunandan and Morrow 1995).

\section{Core flooding}

Table 8 shows the characteristics of the plug used in the flooding test using the device described. Figure 13 shows the amount of oil recovered against the amount of PV injected, and Fig. 14 shows the curvature of the pressure difference between the two ends of the core while injection versus injected PV. In Figs. 13 and 14, the blue part of the curve is related to saline water injection and the red graph is related to injection of TR-880 surfactant at a concentration of $1000 \mathrm{ppm}$ at $351.15 \mathrm{~K}$ with an injection rate of $0.5 \mathrm{cc} / \mathrm{min}$. As can be seen from Fig. 13, total
Fig. 12 Oil drop images sticking onto the carbonate cross section in contact angle tests
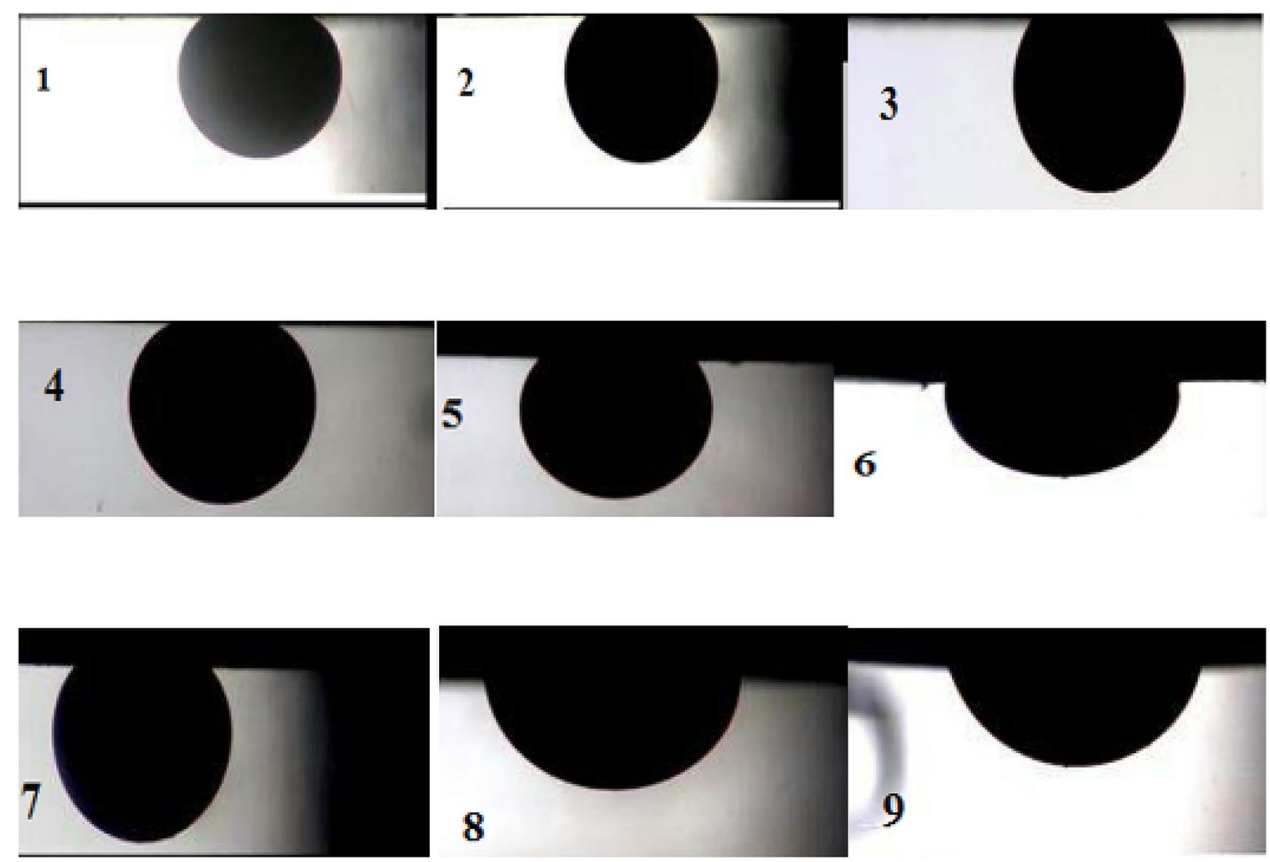
Table 8 Plug specifications used in flooding tests

\begin{tabular}{llllllll}
\hline Perm. (md) & Por. $(\%)$ & $L(\mathrm{~cm})$ & Total $V_{\mathrm{P}}\left(\mathrm{cm}^{3}\right)$ & Mass of dry sample $(\mathrm{g})$ & Plug-saturated mass from oil $(\mathrm{g})$ & $S_{\text {wi }}(\%)$ & OOIP $\left(\mathrm{cm}^{3}\right)$ \\
\hline 25.40 & 22.77 & 7 & 18.07183 & 170.6988 & 189.3670 & 28 & 13
\end{tabular}

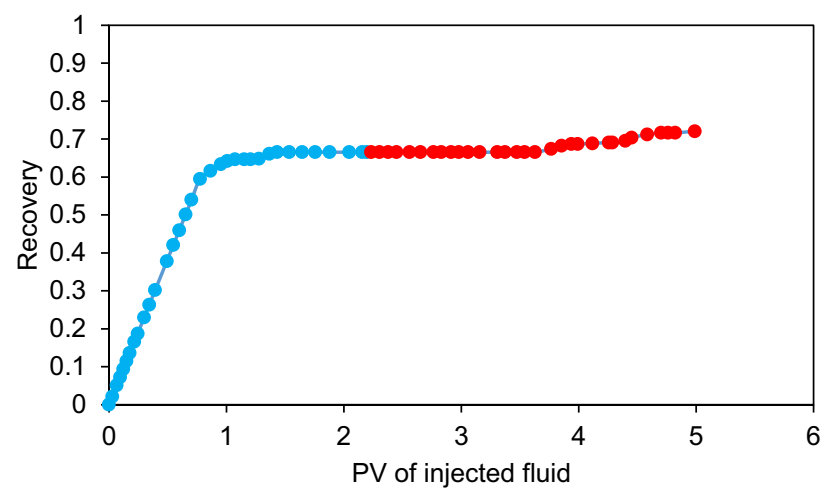

Fig. 13 Amount of production generated by flooding the formation saline water and TR-880 solution at a concentration of $1000 \mathrm{ppm}$ with formation saline water base at a temperature of $351.15 \mathrm{~K}$

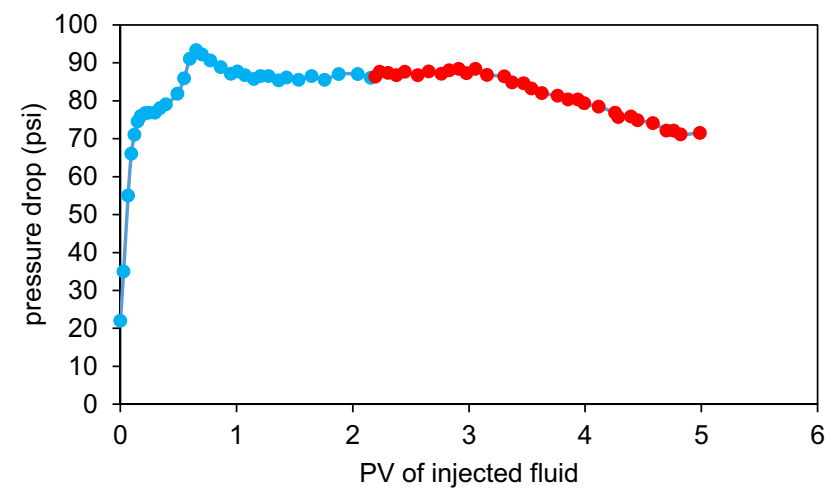

Fig. 14 Pressure drop diagram in the process of saline water and TR-880 solution flooding at $1000 \mathrm{ppm}$ concentration of formation saline water base at $351.15 \mathrm{~K}$

5PV was injected into a saturated core of oil during saline water injection and a solution of surfactant. The amount of secondary recovery of oil from the plug meaning recovery as a result of water flooding is $66.5 \%$ of the oil. This amount has reached about $72 \%$ with the third flooding of surfactant, indicating an increase of $5.5 \%$. The graph of the pressure drop is also followed by a downward trend during the third injection. This can indicate a decrease in the interfacial pressure of the injectable water and oil by the surfactant and subsequently reduction in the capillary pressure in the core.

\section{Conclusion}

The ability of three commercial surfactants, namely AN-120, NX-1510 and TR-880, to reduce interfacial tension and alter the carbonate rock wettability and their efficiency in high salinity based on pendant drop experiments and contact angle were investigated and then compared. The flooding test with an optimum solution for minimum interfacial tension as the main mechanism of surfactants was carried out to obtain the final recovery of oil. According to this:

- Interfacial tension tests show that all surfactants are capable of reducing interfacial tension and their performances are enhanced at high salinity so that with increasing salinity, the CMC and the amount of interfacial tension decrease, and the lowest interfacial pressure of the surfactant solutions from solution with formation water base, the TR- 880 solution, is obtained at a concentration of $1000 \mathrm{ppm}$ at $1.27 \mathrm{mN} / \mathrm{m}$.

- The results of dynamic interfacial tension indicate the dependence of this parameter on time, in which, over time, interfacial tensions show a decreasing trend.

- With temperature changes, a certain trend is observed in the interfacial tension data, so that, by increasing temperature, the interfacial tension increases, although these variations are minor. But with the pressure changes, there is no clear trend in interfacial tension.

- The contact angle test confirms wettability alteration to hydrophilicity, and most of the results are within the range of hydrophilicity. The lowest average contact angle belongs to NX-1510 surfactant solution at $1000 \mathrm{ppm}$ at $27.7965{ }^{\circ} \mathrm{C}$.

- The final recovery rate of the oil in the secondary flooding test with saline water and the third with TR- 880 solution at a concentration of $1000 \mathrm{ppm}$ contains a total of $72 \%$ primary oil, which is $66.5 \%$ for the secondary injection and $5.5 \%$ for the injection of surfactant.

Modeling of dynamic IFT data can be useful to streamline certain experimental workflows, and therefore not need to run as many experiments for different salinities or other formulation variables. Therefore, in future work modeling of dynamic IFT data of this work is suggested. 
Open Access This article is distributed under the terms of the Creative Commons Attribution 4.0 International License (http://creativeco mmons.org/licenses/by/4.0/), which permits unrestricted use, distribution, and reproduction in any medium, provided you give appropriate credit to the original author(s) and the source, provide a link to the Creative Commons license, and indicate if changes were made.

\section{References}

Ahmadi MA, Shadizadeh SR (2013) Implementation of a high-performance surfactant for enhanced oil recovery from carbonate reservoirs. J Petrol Sci Eng 110:66-73

Amirsadat SA, Moradi B, Hezave AZ, Najimi S, Farsangi MH (2017) Investigating the effect of nano-silica on efficiency of the foam in enhanced oil recovery. Korean J Chem Eng 34(12):3119-3124

Austad T, Milter J (1997) Spontaneous imbibition of water into low permeable chalk at different wettabilities using surfactants. In: International symposium on oilfield chemistry, Houston, Texas. Society of Petroleum Engineers. SPE-37236-MS

Ayirala SC, Vijapurapu CS, Rao DN (2006) Beneficial effects of wettability altering surfactants in oil-wet fractured reservoirs. J Petr Sci Eng 52(1-4):261-274

Emadi S, Shadizadeh SR, Manshad AK, Rahimi AM, Mohammadi AH (2017) Effect of nano silica particles on interfacial tension (IFT) and mobility control of natural surfactant (Cedr extraction) solution in enhanced oil recovery process by nano-surfactant flooding. J Mol Liq 248:163-167

Emadi S, Shadizadeh SR, Manshad AK, Rahimi AM, Nowrouzi I, Mohammadi AH (2019) Effect of using Zyziphus spina christi or Cedr Extract (CE) as a natural surfactant on oil mobility control by foam flooding. J Mol Liq 293:111573

Hajibagheri F, Hashemi A, Lashkarbolooki M, Ayatollahi S (2018) Investigating the synergic effects of chemical surfactant (SDBS) and biosurfactant produced by bacterium (Enterobacter cloa$c a e$ ) on IFT reduction and wettability alteration during MEOR process. J Mol Liq 256:277-285

Hezave AZ, Dorostkar S, Ayatollahi S, Nabipour M, Hemmateenejad B (2013a) Dynamic interfacial tension behavior between heavy crude oil and ionic liquid solution (1-dodecyl-3-methylimidazolium chloride $\left(\left[\mathrm{C}_{12} \mathrm{mim}\right][\mathrm{Cl}]+\right.$ distilled or saline water/heavy crude oil)) as a new surfactant. J Mol Liq 187:83-89

Hezave AZ, Dorostkar S, Ayatollahi S, Nabipour M, Hemmateenejad B (2013b) Investigating the effect of ionic liquid (1-dodecyl3-methylimidazolium chloride $\left(\left[\mathrm{C}_{12} \mathrm{mim}\right][\mathrm{Cl}]\right)$ ) on the water/ oil interfacial tension as a novel surfactant. Colloids Surf A Physicochem Eng Asp 421:63-71

Hua XY, Rosen MJ (1988) Dynamic surface tension of aqueous surfactant solutions: I. Basic parameters. J Colloid Interface Sci 124(2):652-659

Hua XY, Rosen MJ (1991) Dynamic surface tension of aqueous surfactant solutions: 3 . some effects of molecular structure and environment. J Colloid Interface Sci 141(1):180-190

Jadhunandan PP, Morrow NR (1995) Effect of wettability on waterflood recovery for crude-oil/brine/rock systems. SPE Reserv Eng 10(01):40-46

Jeribi M, Almir-Assad B, Langevin D, Henaut I, Argillier JF (2002) Adsorption kinetics of asphaltenes at liquid interfaces. J Colloid Interface Sci 256(2):268-272

Joos P, Fang JP, Serrien G (1992) Comments on some dynamic surface tension measurements by the dynamic bubble pressure method. J Colloid Interface Sci 151(1):144-149
Kumar B (2012) Effect of salinity on the interfacial tension of model and crude oil systems. Doctoral dissertation, University of Calgary

Kumar A, Mandal A (2018) Characterization of rock-fluid and fluidfluid interactions in presence of a family of synthesized zwitterionic surfactants for application in enhanced oil recovery. Colloids Surf A Physicochem Eng Asp 549:1-12

Kumar S, Panigrahi P, Saw RK, Mandal A (2016) Interfacial interaction of cationic surfactants and its effect on wettability alteration of oil-wet carbonate rock. Energy Fuels 30(4):2846-2857

Kumar S, Kumar A, Mandal A (2017) Characterizations of surfactant synthesized from Jatropha oil and its application in enhanced oil recovery. AIChE J 63(7):2731-2741

Lashkarbolooki M, Ayatollahi S (2017) Experimental and modeling investigation of dynamic interfacial tension of asphaltenicacidic crude oil/aqueous phase containing different ions. Chin J Chem Eng 25(12):1820-1830

Lashkarbolooki M, Riazi M, Ayatollahi S (2016a) Investigation of effects of salinity, temperature, pressure, and crude oil type on the dynamic interfacial tensions. Chem Eng Res Des 115:53-65

Lashkarbolooki M, Ayatollahi S, Riazi M (2016b) Mechanistic study on the dynamic interfacial tension of crude oil + water systems: experimental and modeling approaches. J Ind Eng Chem 35:408-416

Manshad AK, Olad M, Taghipour SA, Nowrouzi I, Mohammadi AH (2016) Effects of water soluble ions on interfacial tension (IFT) between oil and brine in smart and carbonated smart water injection process in oil reservoirs. J Mol Liq 223:987-993

Manshad AK, Nowrouzi I, Mohammadi AH (2017a) Effects of water soluble ions on wettability alteration and contact angle in smart and carbonated smart water injection process in oil reservoirs. J Mol Liq 244:440-452

Manshad AK, Rezaei M, Moradi S, Nowrouzi I, Mohammadi AH (2017b) Wettability alteration and interfacial tension (IFT) reduction in enhanced oil recovery (EOR) process by ionic liquid flooding. J Mol Liq 248:153-162

Najimi S, Nowrouzi I, Manshad AK, Farsangi MH, Hezave AZ, Ali JA, Keshavarz A, Mohammadi AH (2019) Investigating the effect of $[\mathrm{C} 8 \mathrm{Py}][\mathrm{Cl}]$ and $[\mathrm{C} 18 \mathrm{Py}][\mathrm{Cl}]$ ionic liquids on the water/oil interfacial tension by considering Taguchi method. J Pet Explor Prod Technol. https://doi.org/10.1007/s1320 2-019-0688-8

Nowrouzi I, Manshad AK, Mohammadi AH (2018) Effects of dissolved binary ionic compounds and different densities of brine on interfacial tension (IFT), wettability alteration, and contact angle in smart water and carbonated smart water injection processes in carbonate oil reservoirs. J Mol Liq 254:83-92

Nowrouzi I, Manshad AK, Mohammadi AH (2019a) Effects of ions and dissolved carbon dioxide on wettability alteration, contact angle and oil production by spontaneous imbibition of smart water and carbonated smart water in naturally fractured carbonate oil reservoirs. Fuel 235:1039-1051

Nowrouzi I, Manshad AK, Mohammadi AH (2019b) Effects of $\mathrm{TiO}_{2}$, $\mathrm{MgO}$, and $\gamma-\mathrm{Al}_{2} \mathrm{O}_{3}$ nano-particles in carbonated water on wateroil interfacial tension (IFT) reduction in chemical enhanced oil recovery (CEOR) process. J Mol Liq 292:111348

Nowrouzi I, Manshad AK, Mohammadi AH (2019c) Effects of dissolved carbon dioxide and ions in water on the dynamic interfacial tension of water and oil in the process of carbonated smart water injection into oil reservoirs. Fuel 243:569-578

Nowrouzi I, Manshad AK, Mohammadi AH (2019d) Effects of concentration and size of $\mathrm{TiO}_{2}$ nano-particles on the performance of smart water in wettability alteration and oil production under spontaneous imbibition. J Pet Sci Eng 183:106357

Nowrouzi I, Manshad AK, Mohammadi AH (2020a) Effects of Tragacanth Gum as a natural polymeric surfactant and soluble ions 
on chemical smart water injection in oil reservoirs. J Mol Struct 1200: 127078

Nowrouzi I, Manshad AK, Mohammadi AH (2020b) Effects of $\mathrm{TiO}_{2}$, $\mathrm{MgO}$ and $\gamma-\mathrm{Al}_{2} \mathrm{O}_{3}$ nano-particles on wettability alteration and oil production under carbonated nano-fluid imbibition into carbonate oil reservoirs. Fuel 259:116110

Painter P, Williams P, Mannebach E (2009) Recovery of bitumen from oil or tar sands using ionic liquids. Energy Fuels 24(2):1094-1098

Pal N, Saxena N, Laxmi KD, Mandal A (2018a) Interfacial behaviour, wettability alteration and emulsification characteristics of a novel surfactant: implications for enhanced oil recovery. Chem Eng Sci 187:200-212

Pal N, Saxena N, Mandal A (2018b) Studies on the physicochemical properties of synthesized tailor-made gemini surfactants for application in enhanced oil recovery. J Mol Liq 258:211-224

Putra W, Hakiki F (2019) Microbial enhanced oil recovery: interfacial tension and biosurfactant-bacteria growth. J Pet Explor Prod Technol 9(3):2353-2374

Rostami A, Hashemi A, Takassi MA, Zadehnazari A (2017) Experimental assessment of a lysine derivative surfactant for enhanced oil recovery in carbonate rocks: mechanistic and core displacement analysis. J Mol Liq 232:310-318

Salathiel RA (1973) Oil recovery by surface film drainage in mixedwettability rocks. J Pet Technol 25(10):1-216

Salehi M, Johnson SJ, Liang JT (2008) Mechanistic study of wettability alteration using surfactants with applications in naturally fractured reservoirs. Langmuir 24(24):14099-14107

Schramm LL (ed) (2000) Surfactants: fundamentals and applications in the petroleum industry. Cambridge University Press, Cambridge

Sheng J (2010) Modern chemical enhanced oil recovery: theory and practice. Gulf Professional Publishing, Houston

Spinler EA, Zornes DR, Tobola DP, Moradi-Araghi A (2000) Enhancement of oil recovery using a low concentration of surfactant to improve spontaneous and forced imbibition in chalk. In: SPE/
DOE improved oil recovery symposium, Tulsa, Oklahoma. Society of Petroleum Engineers. SPE-59290-MS

Takassi MA, Zargar G, Madani M, Zadehnazari A (2017) The preparation of an amino acid-based surfactant and its potential application as an EOR agent. Pet Sci Technol 35(4):385-391

Torrealba VA, Johns RT (2017) Coupled interfacial tension and phase behavior model based on micellar curvatures. Langmuir 33(47):13604-13614

Ward AFH, Tordai L (1946) Time-dependence of boundary tensions of solutions I. The role of diffusion in time-effects. J Chem Phys 14(7):453-461

Xu W (2005) Experimental investigation of dynamic interfacial interactions at reservoir conditions. MS thesis, University of Petroleum, China

Yan LM, Cui ZG, Song BL, Pei XM, Jiang JZ (2017) New series of double-chain single-head nonionic surfactants: 1, 3-dialkyl glyceryl ether ethoxylates for surfactant-polymer flooding. Energy Fuels 31(4):3821-3829

Yan LM, Cui ZG, Song BL, Pei XM, Jiang JZ (2018) Improving performances of double-chain single-head surfactants for SP flooding by combining with conventional anionic surfactants. J Dispers Sci Technol 39(1):130-137

Zarkar S, Pauchard V, Farooq U, Couzis A, Banerjee S (2015) Interfacial properties of asphaltenes at toluene-water interfaces. Langmuir 31(17):4878-4886

Zeinolabedini Hezave A, Dorostkar S, Ayatollahi S, Nabipour M, Hemmateenejad B (2014) Mechanistic investigation on dynamic interfacial tension between crude oil and ionic liquid using mass transfer concept. J Dispers Sci Technol 35(10):1483-1491

Publisher's Note Springer Nature remains neutral with regard to jurisdictional claims in published maps and institutional affiliations. 